\title{
Process audits versus product quality monitoring of bulk milk
}

\author{
A. G. J. Velthuis ${ }^{\star 1}$ and M. A. P. M. van Asseldonk† \\ *Business Economics, Wageningen University, Hollandseweg 1, $6706 \mathrm{KN}$, Wageningen, the Netherlands \\ †Agricultural Economics Research Institute, Wageningen University and Research Centre, Hollandseweg 1, 6706 KN, Wageningen, \\ the Netherlands
}

\section{ABSTRACT}

Assessment of milk quality is based on bulk milk testing and farm certification on process quality audits. It is unknown to what extent dairy farm audits improve milk quality. A statistical analysis was conducted to quantify possible associations between bulk milk testing and dairy farm audits. The analysis comprised 64.373 audit outcomes on 26,953 dairy farms, which were merged with all conducted laboratory tests of bulk milk samples 12 mo before the audit. Each farm audit record included 271 binary checklist items and 52 attention point variables (given to farmers if serious deviations were observed), both indicating possible deviations from the desired farm situation. Test results included somatic cell count (SCC), total bacterial count (TBC), antimicrobial drug residues (ADR), level of butyric acid spores (BAB), freezing point depression (FPD), level of free fatty acid (FFA), and milk sediment (SED). Results show that numerous audit variables were related to bulk milk test results, although the goodness of fit of the models was generally low. Cow hygiene, clean cubicles, hygiene of milking parlor, and utility room were positively correlated with superior product quality, mainly with respect to SCC, TBC, BAB, FPD, FFA, and SED. Animal health or veterinary drugs management (i.e., drug treatment recording, marking of treated animals, and storage of veterinary drugs) related to SCC, FPD, FFA, and SED. The availability of drinking water was related to TBC, BAB, FFA, and SED, whereas maintenance of the milking equipment was related mainly to SCC, FPD, and FFA. In summary, bulk milk quality and farm audit outcomes are, to some degree, associated: if dairy farms are assessed negatively on specific audit aspects, the bulk milk quality is more likely to be inferior. However, the proportion of the total variance in milk test results explained by audits ranged between 4 and $13 \%$ (depending on the specific bulk milk test), showing that auditing dairy farms provides additional information but has a limited association with the

Received June 11, 2010.

Accepted September 27, 2010.

${ }^{1}$ Corresponding author: annet.velthuis@wur.nl outcome of a product quality control program. This study suggests that farm audits could be streamlined to include only relevant checklist items and that bulk milk quality monitoring could be used as a basis of selecting farms for more or less frequent audits.

Key words: bulk milk quality, audit, certification scheme, monitoring

\section{INTRODUCTION}

Milk processing industries demand high quality bulk milk from dairy producers because losses can be high if the quality of dairy products is insufficient (Barbano et al., 2006; Velthuis et al., 2009, 2010). Farmers are encouraged to use best management practices, with special attention to feed, water, drugs, and hygiene at milking. Bulk milk is routinely tested and milk payment schemes are based on these test results to stimulate high product quality. Moreover, to ensure first-class process quality on dairy farms, only certified farms are approved to deliver milk for human consumption.

For the routine monitoring of bulk milk a sample from each bulk milk delivery is taken and analyzed in the lab for composition and quality in the Netherlands. The analysis for the composition includes the assessment of fat, protein, lactose, and urea levels. The analysis for quality includes the assessment of SCC, total bacterial count (TBC), antimicrobial drug residues (ADR), level of butyric acid spores (BAB), freezing point depression (FPD), level of free fatty acid (FFA), and milk sediment (SED). Test frequency differs between quality measures, ranging from every delivery (ADR), twice per month (SCC, TBC), once per month (BAB, SED), to twice a year (FPD, FFA). The results accurately reflect product quality and provide an impression of hygiene management at farm level.

Payment schemes are an important incentive in controlling all bulk milk quality parameters that are tested, such as SCC, TBC, ADR, BAB, FPD, FFA, and SED (Veerkamp et al., 1998). Milk payment schemes are also effective motivators to enhance management practices on dairy farm; for example, mastitis management (Valeeva et al., 2007) has improved because of the penalty 
system related to exceeded levels of SCC (Schukken et al., 1992; Nightingale et al., 2008). In the Netherlands, milk price is reduced by $\$ 0.33$ (€0.25) to $\$ 0.50$ (€0.38) per $\mathrm{kg}$ of milk for the month if ADR are detected. A penalty of $\$ 0.007$ (€0.005) per $\mathrm{kg}$ is issued if SCC and FPD exceed the attention limit or if TBC exceeds its first attention limit. Moreover, the milk price is reduced by around $\$ 0.013$ (€0.01) per $\mathrm{kg}$ if BAB, FFA, or SED exceeds the attention limit or when TBC exceeds its second attention limit.

Other important tools for improving bulk milk quality are quality assurance programs or certification schemes for dairy farms. The aim of these certification schemes is to reach a defined performance demanded by milk processors and to make customers and consumers aware of the performance level (Meuwissen et al., 2003). Such programs include farm audits in which farms are assessed using detailed checklists. In others, the hygienic status of farm, including the milking equipment, milking parlor, utility room, feed and water management, and veterinary drug usage are assessed. Auditing these management practices is considered important in producing high quality milk (Herrick, 1993). Certification schemes for dairy farms not only judge farm aspects that are related to milk quality, but also assess the status of animal health and animal welfare. Audits are thought to motivate farmers to refine management procedures. Management practices used to improve milk quality involve multiple factors related to hygiene of the milking environment, hygiene of the environment in which cows are housed, hygiene of the milking equipment, udder hygiene, and cow health.

Monitoring bulk milk and certification schemes aim to improve bulk milk quality. However, it is unknown whether and to what extent certification schemes relate to bulk milk quality. Therefore, the goal of this study was to quantify the relation between dairy farm audits and milk quality monitoring, wherein audit outcomes were compared with bulk milk test results.

\section{MATERIALS AND METHODS}

Data was provided by Qlip NV (Leusden, the Netherlands), the Dutch organization responsible for the certification and auditing of dairy farms and testing farm milk deliveries to the processors for protein, fat, lactose, urea, SCC, TBC, ADR, BAB, FPD, FFA, and SED. One data set contained the results of all dairy farm audits and the other contained bulk milk test results of all farm milk deliveries to the processors. The merged data set included 64,373 farm audits conducted on 26,953 farms between January 2002 and April 2008 and all related test results of the bulk milk samples 12 mo before the audit.

\section{Farm Audit Data}

Each farm audit record included 271 binary checklist items (class variables) that indicated a possible deviation (1) from the desired farm situation (0). For example, the checklist item "Utility room is dirty" had a value of 1 if the auditor observed dirt in the utility room, otherwise it had value of 0 (which is the desired farm situation). These checklist items were distributed over 52 categories and the summary statistics are depicted in the left part of Table 1. For example, within the category "Farm hygiene-clothing" 2 checklist items were scored as deviant 93 and 57 times during 64,373 farm audits, respectively. In summary, only $0.23 \%$ of all farm audits had a deviation from the desired farm situation under this category.

Additionally, the data set included 52 integer variables with the number of attention points given to a specific farm category where the baseline value was 0 (right part of Table 1). For example, in the category "Farm hygiene-clothing," 160 farm audits (or 0.25\% of all audits) resulted in from 1 to a maximum of 50 possible attention points. The maximum number of points given during a farm audit to this category was 8 , whereas the mean number of points given over all farm audits was 0.01 with a standard deviation of 0.19 attention points.

Next to the audit variables listed in Table 1 are other variables included in the analysis for statistical correction, namely auditor $(\mathrm{n}=47)$, audit type $[\mathrm{n}=14$; regular audit, re-introduction audit, start audit, second audit (6 subtypes), inspection, regional inspection (2 subtypes), short audit, refusal], audit result $(\mathrm{n}=3$; approved, rejected, blocked), and 39 dairy processing plant numbers.

For most individual audit variables, only a small percentage of the 64,373 audits showed deviation (the "\% Dev" columns in Table 1), whereas $64.5 \%$ of farms received at least one attention point given by total number of points at the bottom of Table 1 .

\section{Bulk Milk Laboratory Result Data}

For ease of analysis, test results 12 mo before each farm audit of SCC, TBC, ADR, BAB, FPD, FFA, and SED were aggregated into summary variables (Figure 1). For SCC, TBC, FPD, and FFA the average (AVG), standard deviation (SD), median and maximum were calculated. For ADR, BAB, and SED, the number of test results that exceed the attention level was counted (SUM). The various laboratory result variables cover the period between January 1, 2002, and April 1, 2008. Table 2 shows only the aggregated laboratory result variables of the 7 models presented in this paper, al- 
Table 1. Descriptive statistics of the checklist item variables and attention point variables of 64,373 farm audits

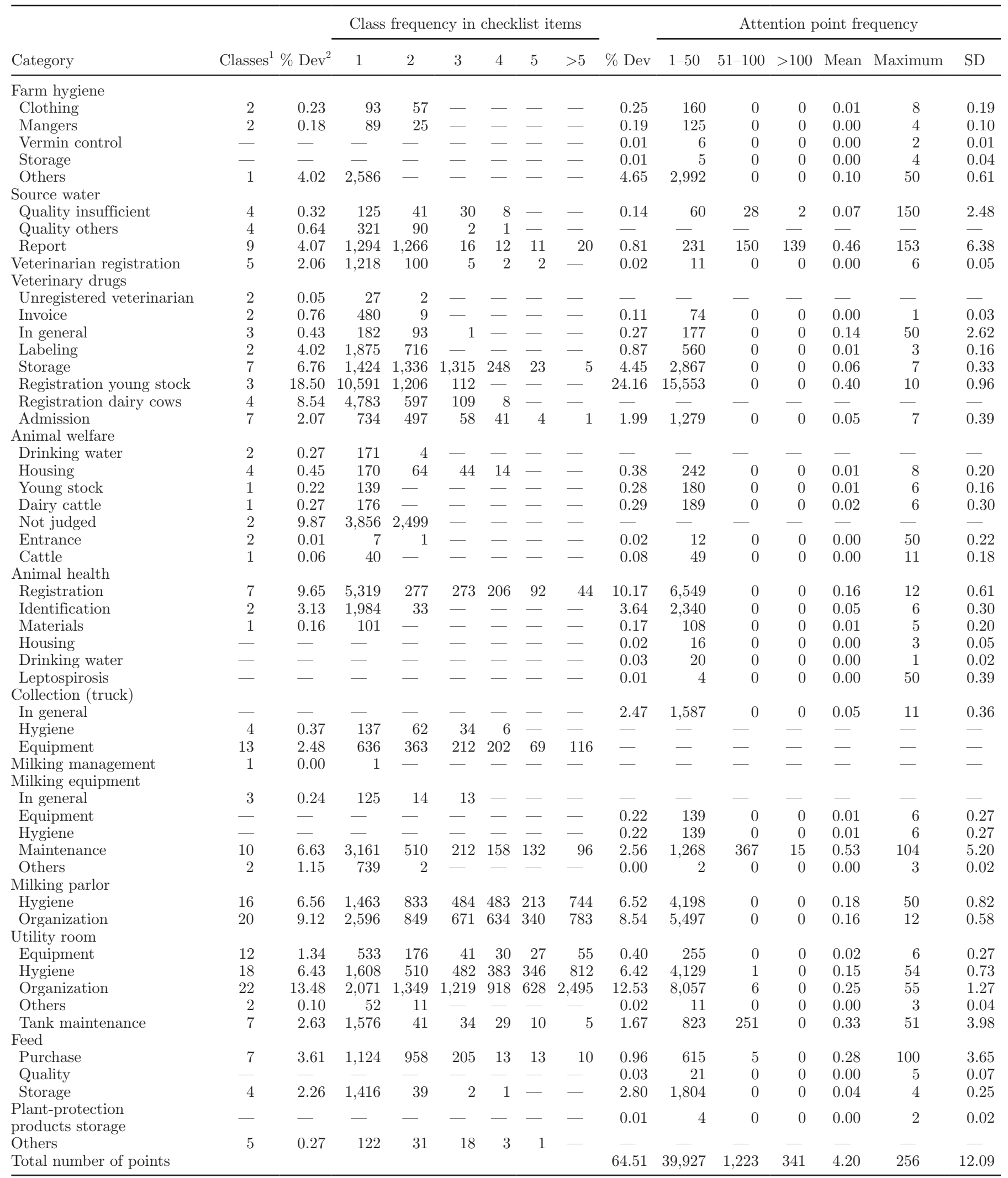

${ }^{1}$ Number of checklist points within a category.

${ }^{2}$ Percentage of farm audits with a deviation within the category. 
Table 2. Summary statistics of the laboratory result variables of bulk milk per audit

\begin{tabular}{lccccc}
\hline Variable $^{1}$ & Records, $\mathrm{n}$ & $\begin{array}{c}\text { Records } \\
\text { not null, }\end{array}{ }^{2} \%$ & Minimum & Average & Maximum \\
\hline SCC12AVG & 49,987 & 100.00 & 19 & 220 & 1,038 \\
TBC12AVG & 62,404 & 100.00 & 0 & 10 & $999^{3}$ \\
ADR12SUM & 63,255 & 7.40 & 0 & 0 & 16 \\
BAB12SUM & 49,410 & 45.44 & 0 & 1 & 15 \\
FPD12AVG & 59,289 & 100.00 & 333 & 521 & 547 \\
FFA12AVG & 45,102 & 100.00 & 8 & 43 & 824 \\
SED12SUM & 62,365 & 1.48 & 0 & 0 & 8 \\
\hline
\end{tabular}

${ }^{2}$ Percentage of records that were not null in the database.

${ }^{1}$ First 3 characters represent a milk quality criterion, the number in the middle the period in months before a farm audit, and the last 3 characters the summary statistic (average, AVG, or number of times the attention limit is exceeded, SUM) of test results of the criterion during the defined period; SCC $=$ somatic cell count $(\times$ $1,000$ cells $/ \mathrm{mL}), \mathrm{TBC}=$ total bacterial count $(\times 1,000$ cells $/ \mathrm{mL}), \mathrm{ADR}=$ presence of antimicrobial drug residues (no. in period), $\mathrm{BAB}=$ level of butyric acid bacteria (no. in period), FPD $=$ freezing point depression $(\times$ $\left.-1 / 100^{\circ} \mathrm{C}\right), \mathrm{FFA}=$ level of free fatty acid $(\mathrm{mmol} / 10.000 \mathrm{~g}$ of fat $)$, and $\mathrm{SED}=$ milk sediment (no. in period).

${ }^{3}$ The maximum is probably $>999$ because the display had only 3 numbers.

though 60 models were fitted in total. For example, the variable SCC12AVG represents the average of the SCC results of 24 tank milk samples delivered in 12 mo before a farm audit. Hence, the minimum SCC12AVG (in units of 1,000 cells $/ \mathrm{mL}$ ) was 19 , the average 220 , the maximum 1,038, and the number of missing values was 14,385 (most of farm audits during the first months of 2002).

Somatic cell count was tested twice a month. The SCC test was done by adding a colorant to the milk and counting automatically the glowing cells under a microscope. The test was done with the Fossomatic 5000 (Foss A/S, Hillerød, Denmark). A good SCC was $<150,000$ cells $/ \mathrm{mL}$, whereas the attention level was 250,000 cells $/ \mathrm{mL}$, as set by the milk processing companies.

Total bacterial count is tested twice a month. It counts the total number of bacteria in the bulk milk and is a measure of hygiene during milking and storage of milk. The number of bacterial colonies was automatically counted with a Bactoscan FC (Foss A/S), where the conversion of resulting Bactoscan units to standard plate count units was in conformity with ISO 21187|IDF 196 (ISO, 2004). Good quality bulk milk had a TBC of $20,000 \mathrm{cfu} / \mathrm{mL}$, whereas the first attention level was $100,000 \mathrm{cfu} / \mathrm{mL}$ and the second $250,000 \mathrm{cfu} / \mathrm{mL}$, as set by the milk processing companies.

Antibiotic drug residues are tested for each delivery of bulk milk. All samples were tested with a microbiological test according to the ISO/TS 26844-IDF/RM 215 standard (ISO, 2006). Suspicious samples were tested further with disk assay methods for $\beta$-lactams, sulfonamides, aminoglycosides, macrolides, and tetracyclines as described by Nouws et al. (1999). Applied penalty limits with these disk assays were $0.0037 \mathrm{IU} / \mathrm{mL}$ for benzylpenicillin, $100 \mu \mathrm{g} / \mathrm{kg}$ for sulfamethazine, $100 \mu \mathrm{g} /$

Test results of a fictitious farm

Summary variable

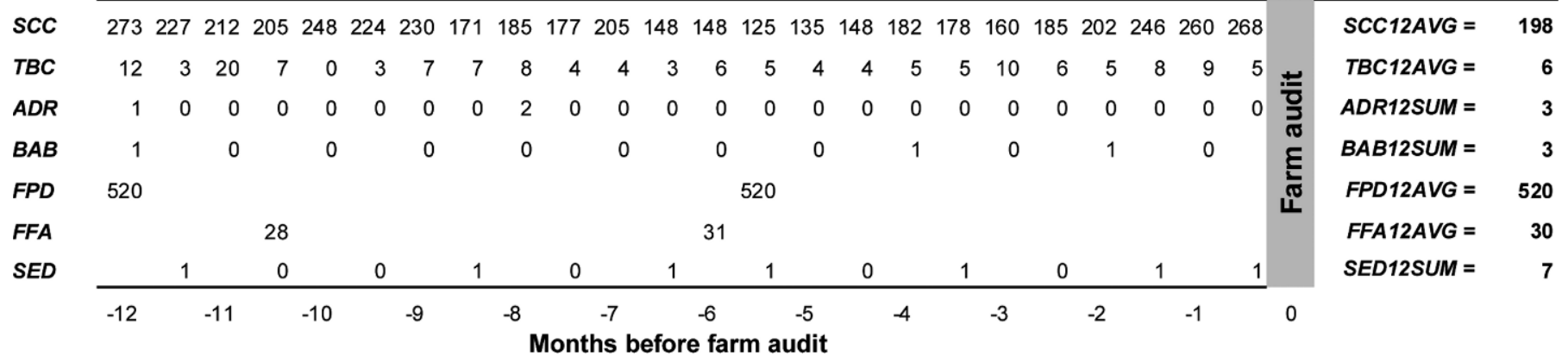

Figure 1. Test results of a fictitious farm to demonstrate the aggregation of test results to a summary variable. Summary variables: first 3 characters represent a milk quality criterion, the number in the middle the period in months before a farm audit (e.g., 12 mo), and the last 3 characters the summary statistic (average, AVG, or number of times the attention limit is exceeded, SUM) of test results of the criterion during the defined period; $\mathrm{SCC}=$ somatic cell count $(\times 1,000$ cells $/ \mathrm{mL}), \mathrm{TBC}=$ total bacterial count $(\times 1,000$ cells $/ \mathrm{mL}), \mathrm{ADR}=$ presence of antimicrobial drug residues (no. in period), $\mathrm{BAB}=$ level of butyric acid bacteria (no. in period), $\mathrm{FPD}=$ freezing point depression $\left(\times-1 / 100^{\circ} \mathrm{C}\right), \mathrm{FFA}$ $=$ level of free fatty acid (mmol/100 g of fat), and SED = milk sediment (no. in period). 
$\mathrm{kg}$ for neomycin, $20 \mu \mathrm{g} / \mathrm{kg}$ for erythromycin, and 50 $\mu \mathrm{g} / \mathrm{kg}$ for oxytetracycline. A positive test resulted in a penalty to the farmer.

The level of butyric acid spores was tested once a month and is a measure for silage quality, which is influenced by housing hygiene. The level of BAB (including other gas-forming bacteria in the milk) was determined by adding a growth medium to the milk that makes spores of butyric acid bacteria germinate after heating to $80^{\circ} \mathrm{C}$. This results in gas formation that can be assessed after $4 \mathrm{~d}$. Two tubes per sample were tested resulting in 3 possible outcomes: $-/-,+/-$, and $+/+$. A good level of BAB was $-/-$, and the attention levels were $+/-$ and $+/+$, as set by the milk processing companies.

Freezing point depression was tested twice a year; FPD is an indicator for possible contamination of bulk milk with water according to ISO 5764-IDF 108 (ISO, 2009). The freezing point of milk is within narrow limits because it depends highly on the composition of blood that flows through the udder, which is very constant. A small percentage of extra water in the milk is thereby detected instantly.

The level of free fatty acids was tested twice a year. Free fatty acids originate from lipolysis of milk fat: a high level of FFA makes the milk rancid. The level of FFA was determined by making an infrared measurement. Bulk milk was valued highly if the level of FFA was below $0.5 \mathrm{mmol} / 100 \mathrm{~g}$ of fat, whereas the attention level was $1.0 \mathrm{mmol} / 100 \mathrm{~g}$ of fat, as set by the milk processing companies.

Milk sediment (SED), a measure of cleanliness during milking, was tested once a month. Milk sediment was tested according to the regulations of the Dutch Dairy Board (http://www.prodzuivel.nl/Engels/DutchDairyBoard2009.pdf) by a filtration test in which the milk is sucked through a filter of cotton wool, which is then visually assessed for sediment. When milk was contaminated with, for example, sand, hair, skin flakes, or straw, the SED is classified was 2 (with sediment), which was the attention level set by the milk processing companies, whereas, when the milk was clean it was classified as class 1.

\section{Statistical Analysis}

A multivariable regression analysis is used to test the relation between the dependent variable (i.e., a bulk milk test result variable) and predictor variables (i.e., the audit variables).

Variable FPD12AVG was normally distributed and therefore the model is written as

$$
y=\beta_{0}+\beta_{1} \cdot x_{1}+\ldots+\beta_{p} \cdot x_{p}+e,
$$

where $y=$ a specific bulk milk test (i.e., FPD12AVG), $\beta_{0}=$ the constant, $\beta_{1}=$ the estimate of audit variable $x_{1}, \beta_{p}=$ the estimate of audit variable $x_{p}$, and $e=$ the error term.

The variables SCC12AVG, TBC12AVG, and FFA12AVG were not normally distributed. The model for the natural logarithm of $S C C 12 A V G$ is written as

$$
y=\operatorname{Exp}\left(\beta_{0}+\beta_{1} \cdot x_{1}+\ldots+\beta_{p} \cdot x_{p}+e\right) .
$$

For the tenth logarithm of TBC12AVG and FFA12AVG, the following models were applied:

$$
y=\log \left(\beta_{0}+\beta_{1} \cdot x_{1}+\ldots+\beta_{p} \cdot x_{p}+e\right) .
$$

Variables for ADR12SUM, BAB12SUM, and SED12 SUM were counts and were therefore Poisson distributed. For these variables, a Poisson regression model was fitted using the log-link function (herein referred to as LogLink). These models can be written as

$$
L N[E(y)]=\beta_{0}+\beta_{1} \cdot x_{1}+\ldots+\beta_{p} \cdot x_{p}+e .
$$

First, all audit variables were tested in a univariable analyses and ranked based on their $P$-values. The audit variables with $P>0.25$ were excluded from the multivariable analyses. Second, all selected audit variables were included in the model as ranked based on the $P$ value in the univariable analyses. Then, variables with highest $P$-values where $P>0.05$ were removed one by one until all variables in the model met the criterion of $P<0.05$ (backward procedure of GENSTAT, 12th ed., VSN International Ltd., Hemel Hempstead, UK). Goodness of fit of the models was determined by the $\mathrm{R}^{2}$ values for the models.

\section{RESULTS}

Based on the goodness of fit of the models, the models for the average values or sums of the 12mo period before a farm audit were chosen to be presented in this paper (Tables 1 and 2). Tables 3 and 4 show the final models for the selected quality variables: $L N(\mathrm{SCC} 12 \mathrm{AVG}), \quad \log (\mathrm{TBC} 12 \mathrm{AVG})$, LogLink(ADR12SUM), LogLink(BAB12SUM), FPD12AVG, Log(FFA12AVG), and LogLink(SED12SUM). All models are presented in comparison to a farm that delivers milk to processing plant A, is judged by auditor A for a standard audit, and is approved without any deviation (the baseline situation). 
Some audit variables did not have a significant relationship with any of the test results. For the checklist variables, this was the case for the following 8 variables: Farm hygiene-storage, Source water-quality others, Veterinary drugs-unregistered veterinarian, Animal health-housing, Milking management, Milking equipment-in general, Milking equipment-equipment, and Milking equipment-hygiene. These variables are not depicted in the results given in Tables 3 and 4 . Within the attention point variables, more audit variables did not relate to any laboratory result variable. On the other hand, 3 categories did relate to all laboratory result variables (i.e., Veterinary drugs-in general, Animal health-registration, and Milking parlor-hygiene) and 3 categories related to 6 out of 7 laboratory result variables (i.e., Veterinary drugs-storage, Veterinary drugs-young stock records, and Animal welfare-dairy cattle).

The final model for $L N(\mathrm{SCC} 12 \mathrm{AVG})$ included a constant, the milk processing plant, the auditor, audit type, audit result, and the variables that are given in Table 3. Farms on which a second audit was performed had increased levels of SCC. In addition, disapproved farms had increased SCC levels, and blocked farms (i.e., those farms not allowed to deliver bulk milk) had the highest levels of SCC. In total, 48 variables as listed in Table 1 were significantly related to SCC numbers. For example, within the variable Milking equipment-hygiene, 3 out of 16 checklist items were statistically significantly related to SCC. It was estimated that $L N(\mathrm{SCC} 12 \mathrm{AVG})$ increased by 0.04 up to 0.27 for these significant checklist items, which is equivalent to 211,000 up to 266,000 cells/mL. The 15 most influential audit variables (i.e., where the expected value deviated most from the baseline situation) for SCC are depicted in Figure 2.

Results show that if the milking parlor, utility room, mangers, feed mixer, feed alley, milking clusters, or the dairy cows were dirty, SCC was increased. For example, if a farm had a dirty milking parlor (as a single deviation) it had an estimated SCC of 266,000 cells $/ \mathrm{mL}$. Furthermore, if maintenance of the (automatic) milking system was poor (reports are missing), SCC was increased. If no veterinary drugs or no animal health registration or veterinary records were present because the farmer thought that there were no diseased animals, SCC was also increased.

The final model for $\log (\mathrm{TBC} 12 \mathrm{AVG})$ included a constant, the auditor, audit type, audit result, and the variables listed in Table 3 . In total, 117 variables as listed in Table 1 were significantly related to TBC. The 15 most influential ones are ranked in Figure 3.

It can be concluded that if the utility room was managed poorly (i.e., numerous flies or vermin were present, if the tank cooling computer had no separate electricity supply, or if the tank or its faucet was outside), TBC was increased. For example, if there were many flies in the utility room, the expected value for the average TBC in the 12 mo before the audit was $100,000 \mathrm{cfu} /$ $\mathrm{mL}(100 \times 1,000 \mathrm{cfu} / \mathrm{mL})$. Also, if the milk equipment was managed poorly or if the utility room was dirty or had no door, TBC was increased. Moreover, the cattle management was also important: if cattle had no free access to drinking water, had dirty cubicles, or if the feed storage was dirty, TBC was also increased.

The sum of ADR in the 12 mo prior to a farm audit, LogLink(ADR12SUM), included the variables as listed in Table 3, a constant, audit type, and audit result. Higher values for ADR12SUM were related to an audit type "an additional audit" and an audit result "disapproved." In total, 12 variables as listed in Table 1 related to the number of bulk milk deliveries testing positive for ADR in the 12 mo prior to a farm audit. These are ranked based on their effect in Figure 4.

The risk of ADR was decreased if there were no records of drug treatment present (and where the farmer indicated that there were no diseased cattle present), if a failure was observed in the recording of drug treatments for dairy cattle (for drugs with a meat withholding time), if the dairy cattle were dirty, and if a failure was observed in the recording of drug treatments for young stock (for drugs with no withholding time). However, the risk of ADR was increased if a failure was observed in the recording of drug treatments for dairy cattle and young stock (for drugs with a milk withholding time), if disinfection possibilities for materials were insufficient, and if attention points were given to the marking of treated animals, to the recording of drug treatment, to the milking parlor hygiene, or to veterinary drug management in general.

The final model for the number of times that $\mathrm{BAB}$ are found in bulk milk in 12 mo before an audit, LogLink(BAB12SUM), included a constant, audit type, and the variables as given in Table 3 . Farms with a second audit had higher BAB levels. In total, 35 variables as listed in Table 1 were significantly related to the level of BAB. The 15 most influential variables are ranked in Figure 5.

It can be concluded that dirty dairy cattle, dirty cubicles for dairy cattle and young stock, and no free access for cattle to drinking water increased the BAB levels. In addition, if the milk pipeline was dirty or crossed a feed alley, dung place, or cellar, BAB levels were also increased. If the management of veterinary drugs and application materials was poor, BAB levels were also increased; however, the BAB level was decreased when the Good Veterinary Practice statement of the supplier was missing. 
Table 3. Estimates of the normalized models ${ }^{1}$ for SCC, total bacterial count (TBC), antimicrobial drug residues (ADR), and the level of butyric acid spores (BAB)

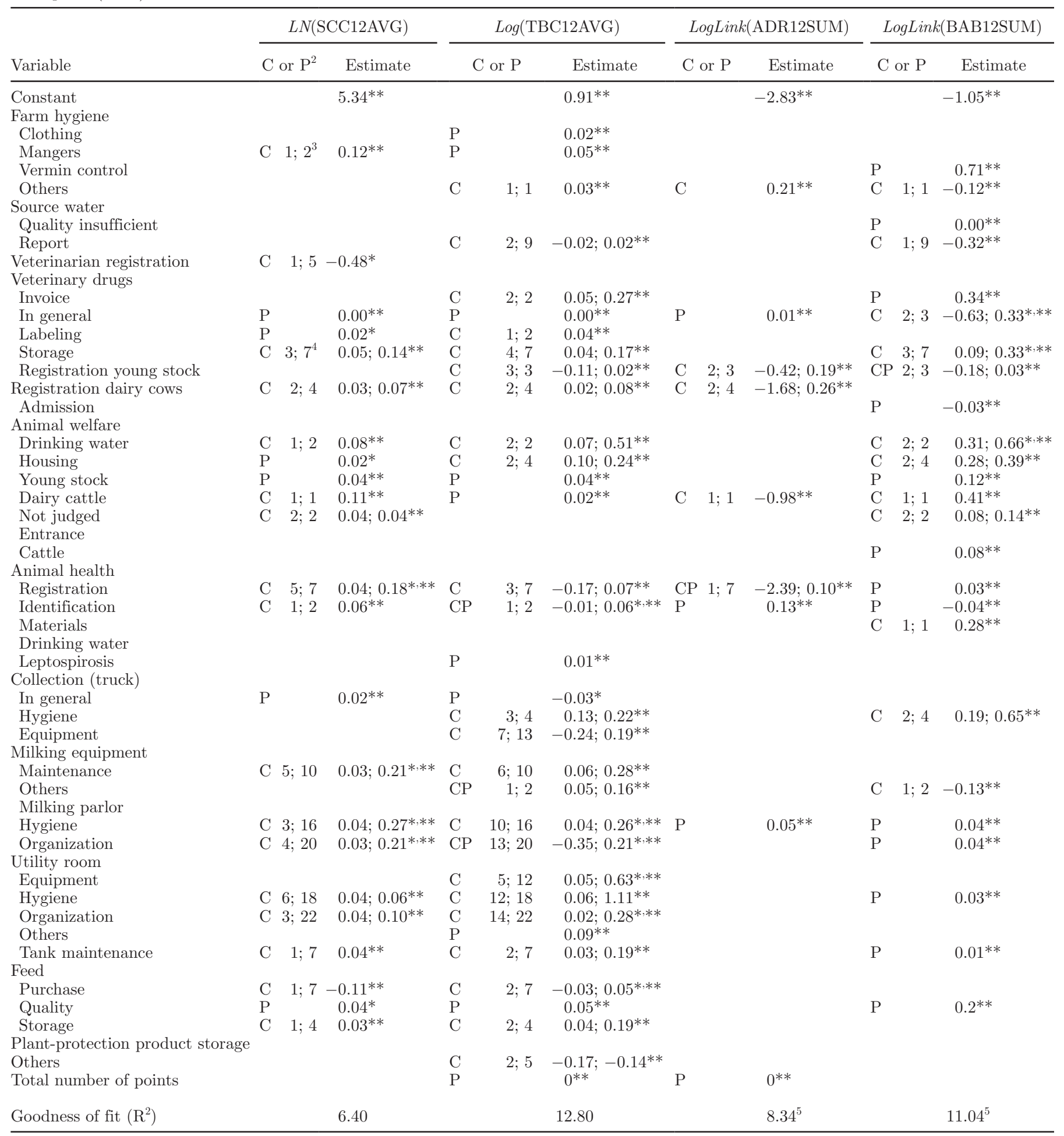


Table 3 (Continued). Estimates of the normalized models ${ }^{1}$ for SCC, total bacterial count (TBC), antimicrobial drug residues (ADR), and the level of butyric acid spores (BAB)

${ }^{1} L N, \log$, and LogLink represent the transformation used in the regression $(L N=$ natural logarithm, Log $=$ tenth logarithm, and $L o g L i n k=\log$ link transformation); SCC, TBC, ADR, and BAB represent a milk quality criterion [i.e., SCC $(\times 1,000$ cells $/ \mathrm{mL})$, total bacterial count $(\times 1,000$ cells $/ \mathrm{mL}$ ), presence of antimicrobial drug residues (no. in period), and level of butyric acid bacteria (no. in period), respectively], 12 represents the 12 mo before a farm audit, and AVG or SUM the summary statistic of test results of the criterion during the defined period (i.e., AVG = average and $\mathrm{SUM}=$ number of times that the attention limit was exceeded).

${ }^{2} \mathrm{C}=$ checklist item variable; $\mathrm{P}=$ attention point variable.

${ }^{3}$ Number of classes that differ significantly from having "no deviation" is given relative to total number of deviant classes.

${ }^{4}$ If more classes differ significantly from having "no deviation," the minimum and maximum estimates are given. The standard errors of the estimates are not given due to space limitations.

${ }^{5}$ Regression deviance divided by the total deviance.

${ }^{*} P<0.05 ;{ }^{* *} P<0.001$.

The final model for FPD12AVG included a constant, the auditor, audit type, audit outcomes, and the variables listed in Table 4. Some audit types were related to a lower FPD and others to a higher FPD, whereas farms that were disapproved had a slightly lower FPD. In total, 28 variables as listed in Table 1 were significantly related to FPD. The 15 most influential variables are ranked in Figure 6.

Many different variables were related to an increase in freezing point. If animal well-being was managed poorly, where the cubicles were dirty, the housing was in poor condition, and where the feed storage was dirty and wet, FPD could be increased. Furthermore, if no veterinary drugs were present or if some drugs exceed the expiration date or the farmer indicated that that no diseased animals were present, FPD was increased. The FPD was related to many judgment criteria varying from utility room to the storage of veterinary drugs.

The final model for $\log (\mathrm{FFA} 12 \mathrm{AVG})$ included a constant, the auditor, audit type, audit result, and variables listed in Table 4. In total, 54 variables other than the constant, auditors, audit types, or audit outcomes were related to the FFA level in bulk milk. The 15 most influential variables for the average level of FFA in the 12 mo prior to a farm audit are ranked in Figure 7.

Management (including the maintenance) and the building of the milking parlor and automatic milking systems were associated with higher levels of FFA in bulk milk. In addition, an increase in FFA levels was expected on farms where cattle did not have free access to drinking water and where treated animals were not clearly marked.

The final model for LogLink(SED12SUM) included a constant, the audit result, and variables listed in Table 4. Farms that did not meet the certification standards (i.e., were disapproved) often exceeded the attention level for SED. In total, 14 variables as listed in Table 1 were related to SED; these are ranked in Figure 8. It can be concluded that the cleanliness of bulk milk was worse if young stock were dirty, the drinking management was not adequate, and when the veterinary drugs were poorly managed.

\section{DISCUSSION}

To quantify the relation between dairy farm audits and product quality monitoring, audit outcomes were compared with bulk milk test results. It was shown that numerous audit variables were significantly associated with bulk milk test results. Cleaner cattle, cubicles, milking parlor, and utility room were associated with superior product quality, mainly with respect to SCC, TBC, BAB, FPD, FFA, and SED. Animal health and veterinary drug management were related to SCC, FPD, FFA, and SED; the availability of drinking water to TBC, BAB, FFA, and SED; and maintenance of the milking equipment related mainly to SCC, FPD, and FFA.

An increased SCC in bulk milk may be caused by cows with udder health problems, poor milking technique, or malfunctioning equipment. About $76 \%$ of the variance in SCC can be explained by the effect of the dairy farm (van Schaik et al., 2002), next to season, milk processing plant, and the amount of milk delivered. This high farm effect suggests that a milk quality program at farm level could improve the SCC. Our study suggests that an increased SCC is related to poor hygiene of the milking parlor, utility room, mangers, feed mixer, feed alley, and milking clusters, and to dirty dairy cows. This is in line with the results of Barnouin et al. (2004), who found that hygienic living conditions and strict teat and udder hygiene are related to SCC. Another finding of this study is that maintenance of the (automatic) milking system is important in relation to SCC. Poor maintenance of the milking machine could affect udder health and is therefore possibly related to SCC. This, together with farmers who indicated that there were no diseased animals present and that, consequently, drug treatment records or animal health records were lacking, were indications that SCC could be increased. These findings correspond to the study of Barnouin et al. (2004), where presence of a specialized and attentive herdsman relates to the level of SCC. A surprising result was that having a veterinarian who is not listed in the Good Veterinary Practice register and 
Table 4. Estimates of the normalized models ${ }^{1}$ for freezing point depression (FPD), free fatty acid (FFA), and milk sediment (SED)

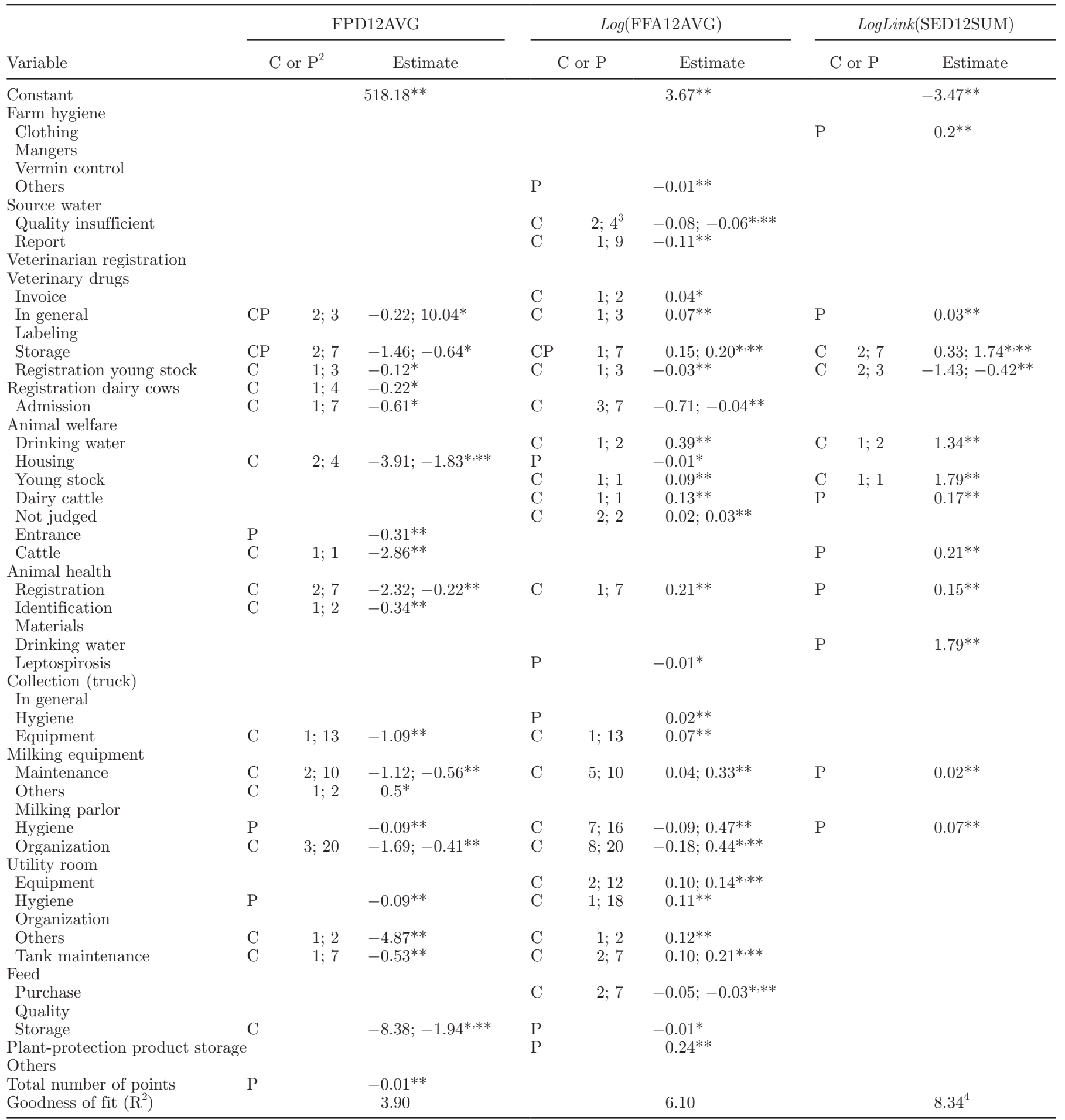

${ }^{1} \log$ and LogLink represent the transformation used in the regression (i.e., Log = tenth logarithm and LogLink = log-link transformation); FPD, FFA, and SED represent a milk quality criterion $\left[F P D=\right.$ freezing point depression $\left(x-1 / 100^{\circ} \mathrm{C}\right), \mathrm{FFA}=$ level of free fatty acid $(\mathrm{mmol} / 10.000 \mathrm{~g}$ of fat), and SED = milk sediment (no. in period)], 12 represents the 12 mo before a farm audit, and AVG or SUM = the summary statistic of test results of the criterion during the defined period (i.e., AVG = average and SUM = number of times that the attention limit was exceeded).

${ }^{2} \mathrm{C}=$ checklist item variable; $\mathrm{P}=$ attention point variable.

${ }^{3}$ Number of classes that differ significantly from having "no deviation" is given relative to total number of deviant classes. If more classes differ significantly from having no deviation, the minimum and maximum estimates are given. The standard errors of the estimates are not given due to space limitations.

${ }^{4}$ Regression deviance divided by the total deviance. 


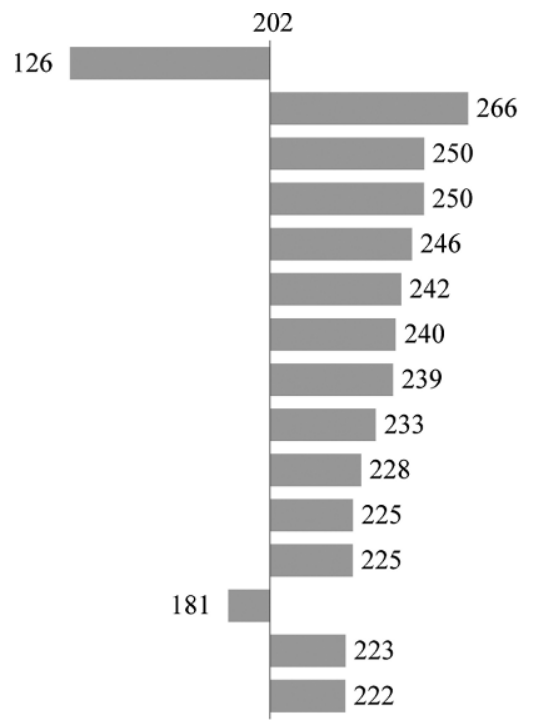

Veterinarian is not listed in the Good-Veterinary-Practice register
Utility room is dirty
Cows are milked above grids that lie over the dung cellar
No winter report of milk equipment present, summer report is present
No summer report of milk equipment present, winter report is present
No animal health recording: farmer indicate no diseased cattle present
(Some) treated animals are not clearly marked
Insufficient or no light in milking parlor
No veterinary drugs in storage for veterinary drugs
Mangers, feed mixer and/or feed alley are dirty
Milking clusters are dirty
Dairy cattle are dirty
Supplier of straw or grass hay is not Good-Manufactory-Practice certified
(Some) reports of automatic-milking systems are missing
Ceiling of machine/tank room is irregular

Figure 2. Most influential audit variables for SCC with expected values for each single deviation from standard. The expected value of SCC was $202(\times 1,000$ cells $/ \mathrm{mL})$.

having a supplier of straw who is not certified in Good Manufacturing Practice were both associated with a lower SCC. No direct explanation can be given for this. In contrast, it is plausible that farms with less focus on hygienic conditions and equipment maintenance might have less focus on quality schemes for service providers such as veterinarians and other suppliers. Improving the level of SCC was possible, but Berry et al. (2006) showed that herds with a certain SCC in one year would likely produce bulk milk with the same level of SCC in the next year, although changes were observed. In addition, a positive correlation between SCC and
TBC existed, suggesting that a reduction in SCC would be associated with reduced TBC (Berry et al., 2006; Pantoja et al., 2009).

It is believed that an increased TBC could be related to careless milking, inadequate cooling, cows with udder health problems, inadequate or no detergent, cold cleaning water, insufficient turbulence during cleaning, blind corners not reached during cleaning, or worn parts of the milking machine. Substantial variance in TBC (i.e., $33 \%$ ) was explained by the dairy farm (van Schaik et al., 2002), suggesting that improvements are possible at the farm level. We showed that an increased TBC

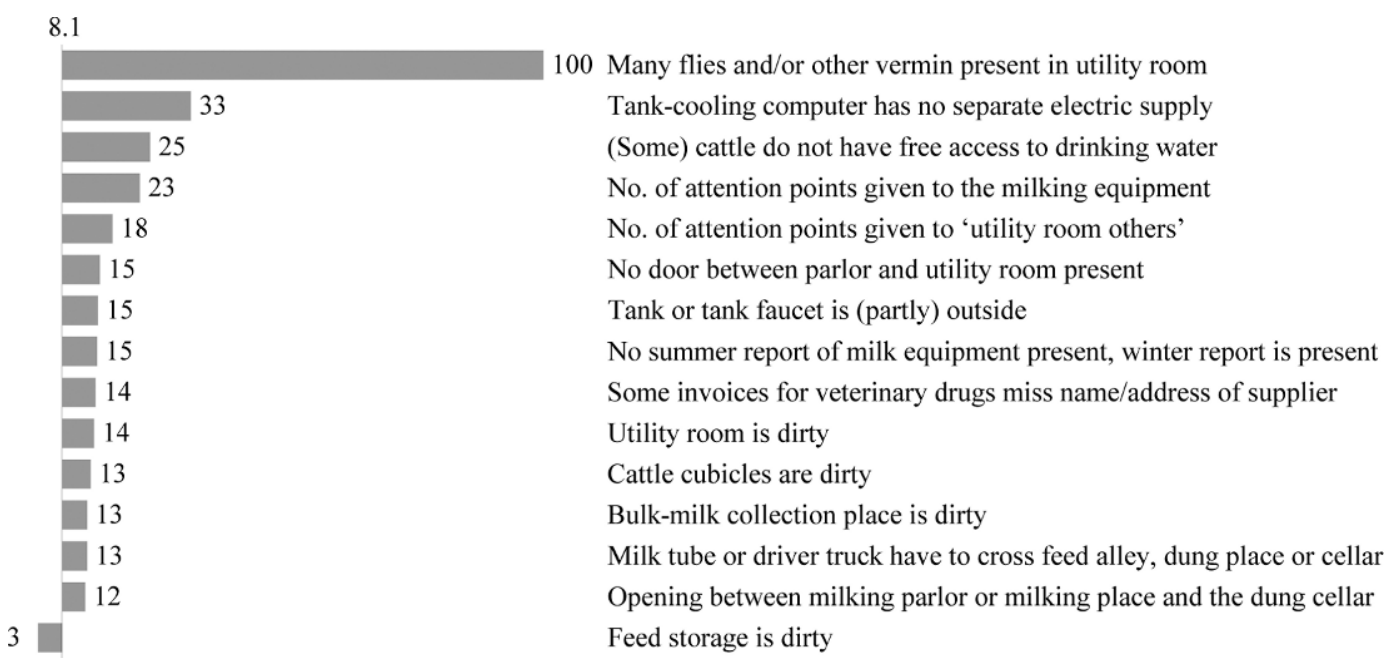

Figure 3. Most influential audit variables for total bacterial count (TBC) with expected values indicated for each single deviation from the standard. The expected value for TBC was $8.1(\times 1,000$ cells $/ \mathrm{mL})$. 


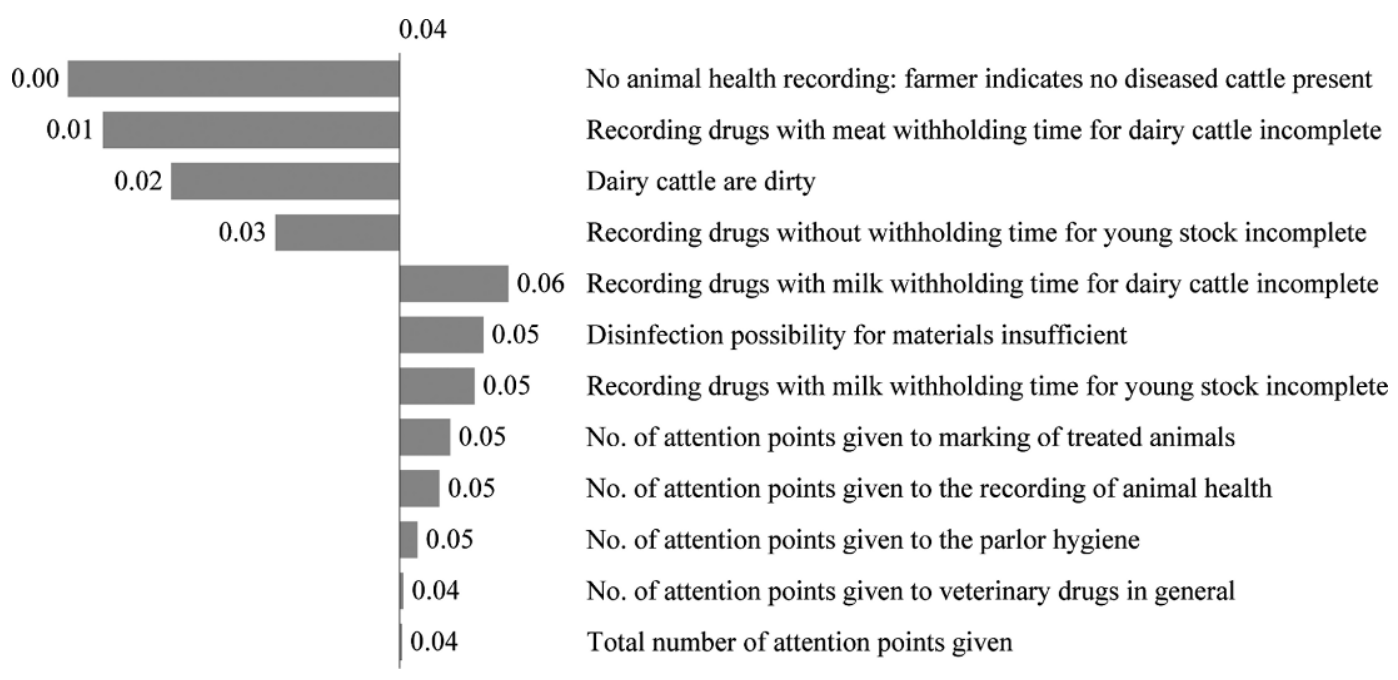

Figure 4. Most influential audit variables for the presence of antibiotic drug residues (ADR) with expected values for each single deviation from the standard. The expected value for ADR was 0.04 times detected in 12 mo.

was related to poor management of the utility room (i.e., numerous flies or vermin present, the tank cooling computer had no separate electricity supply, or the tank or its faucet was outside). Moreover, an increased TBC was also related to poor management of milk equipment and the utility room. According to Elmoslemany et al. (2009a), washing factors of the milk equipment (i.e., reduced alkalinity of wash water and high temperature of detergent wash water) were the important factors. Our results showed also that cattle management (i.e., if cattle had no free access to drinking water, had dirty cubicles, or if the feed storage was dirty) was related to TBC. All relationships were in line with other studies indicating that an increased TBC could be caused by bacterial growth on unsanitary milk equipment and by contamination from dirty udders (Elmoslemany et al., 2009a,b; Pantoja et al., 2009). Total bacterial count was also an indicator of fecal contamination, wherein dirty udders were a source of fecal contamination and often indicated inadequate premilking cow preparation (Elmoslemany et al., 2009a,b).

Antibiotic drug residues are a result of treating dairy cattle with antibiotics and not withholding milk. The presence of ADR in bulk milk may be prevented by complying with the set withholding period of antibiotics, comprehensive veterinary registration, clear marking of treated animals, thorough rinsing of the milking equipment that is used for treated animals, and
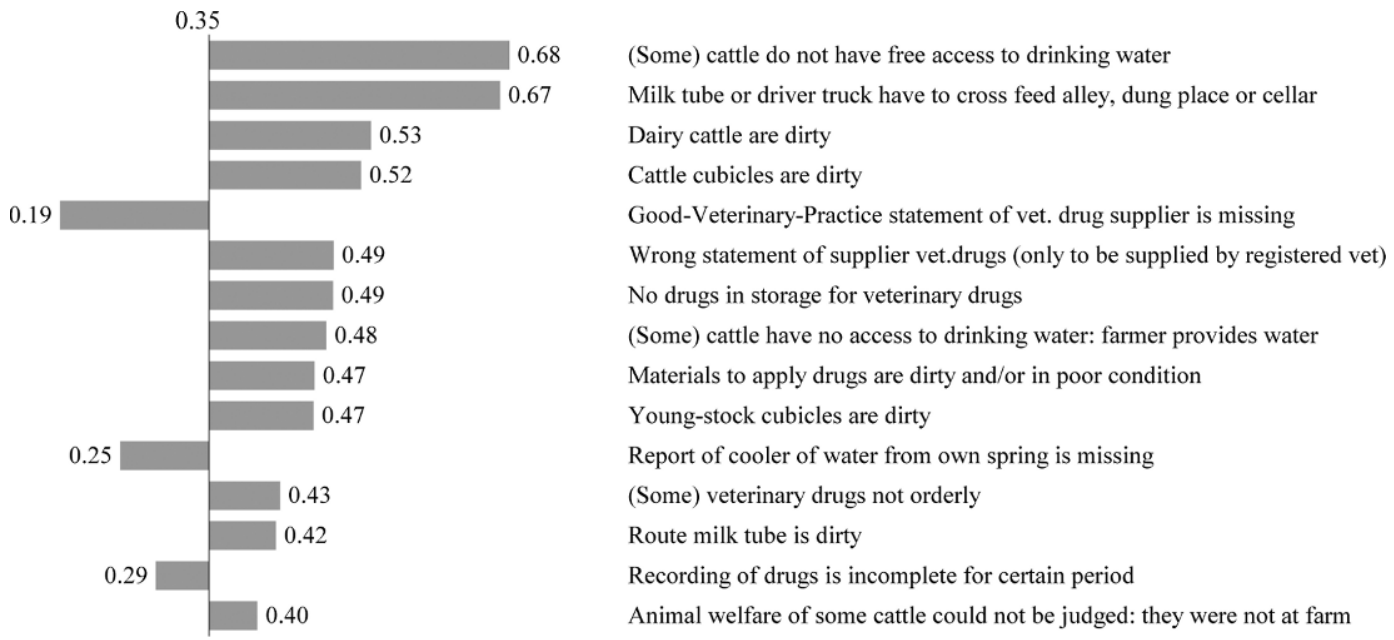

Figure 5. Most influential audit variables for the level of butyric acid spores (BAB) with expected values for each single deviation from the standard. The expected value for $\mathrm{BAB}$ was 0.35 times detected in $12 \mathrm{mo}$. 


\begin{tabular}{c|c}
\hline \multirow{4}{*}{-0.529} & -0.518 \\
\hline & -0.514 \\
& -0.515 \\
& -0.516 \\
& -0.516 \\
& -0.517 \\
& -0.517 \\
& -0.517 \\
& -0.517 \\
-0.520 & \\
& -0.517 \\
& -0.517 \\
& -0.517 \\
& -0.518
\end{tabular}

Wrong statement of supplier vet.drugs (only to be supplied by registered vet)

Feed silo is leaking

Tank faucet and/or tank manhole are not judged due to ongoing cleaning

Housing of (some) cattle is dirty or is in poor condition

Animal welfare condition of cattle is unsatisfactory

No animal health recording: farmer indicates no diseased cattle present

Feed storage is dirty or wet

Cattle cubicles are dirty

Opening between parlor or cow-milking place and the dung cellar

No drugs in storage for veterinary drugs

Good-Veterinary-Practice statement of vet. drugs supplier is missing

Milking parlor floor is irregular or not used

(Some) reports of automatic-milking systems are missing

Tank cooling computer is off

Expiration dates of some veterinary medicines are exceeded

Figure 6. Most influential variables for freezing point depression (FPD) with the estimated values for each single deviation from the standard. The expected value for $\mathrm{FPD}$ was $-0.518^{\circ} \mathrm{C}$.

ensuring good working valves in the milk lines. Our results showed that if cattle were not treated (because the farmer believed that there were no diseased cattle present), the risk of ADR in bulk milk decreased significantly. Furthermore, inadequate marking of treated animals and inadequate health and treatment records increased the ADR risk, probably because making the mistake of not withholding milk of treated dairy cattle is easily made in these circumstances. It has been shown in the literature that a lack of adequate treatment records is a high risk factor for ADR (Sischo et al., 1997). Moreover, Sischo et al. (1997) indicated that a lack of knowledge or understanding of how to use antibiotics and a poor relationship between veterinarians and dairy farmers also increases the risk of ADR.

Surprisingly, our results indicated that poor registration of veterinary drugs used for dairy cattle decreased the risk of ADR, whereas inadequate recording of veterinary drugs for young stock increased the risk of having ADR in bulk milk. We cannot explain this result, but these anomalies may have occurred because of limited observations: only 9\% of the ADR12SUM records were not null.

Changing habits in relation to drug treatments on farms is difficult. It was shown that dairy farmers participating in a quality assurance program (with

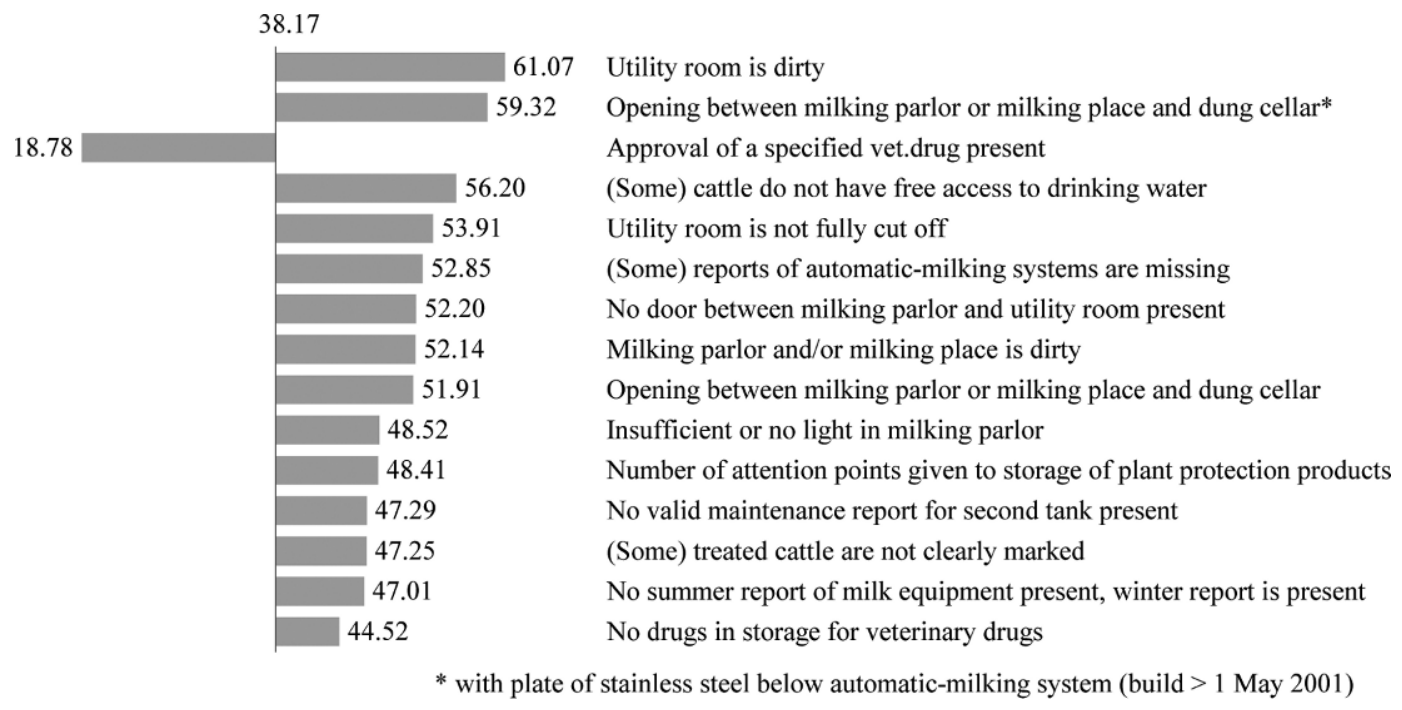

Figure 7. Most influential variables for the level of free fatty acids (FFA) with the estimated values for each single deviation from the standard. The expected value for FFA was 38.17 ( $\mathrm{mmol} / 100 \mathrm{~g}$ of fat). 


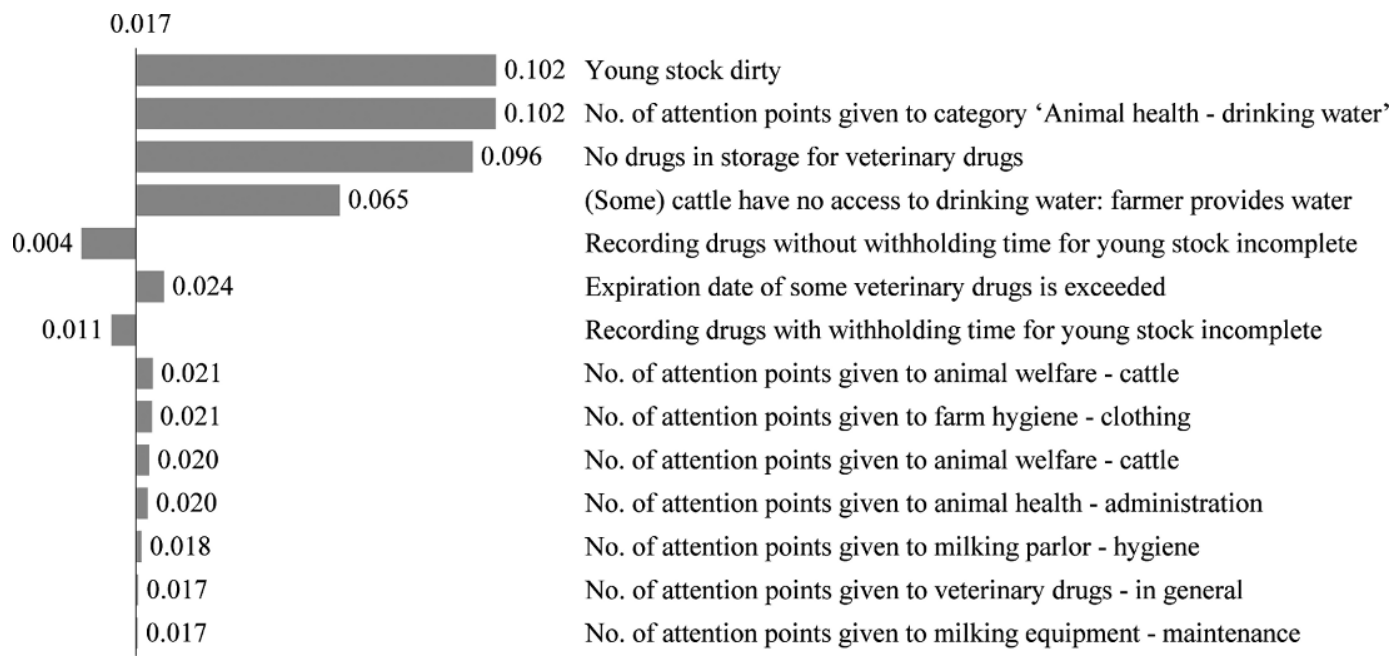

Figure 8. Most influential variables for sediment in milk (SED) with the estimated values for each single deviation from the standard. The expected value for SED was 0.017 times detected in 12 mo.

certification) adopted only a few prudent drug use practices, even though special materials were developed and offered to assist in disease prevention and residue prevention practices on the farm (Gibbons-Burgener et al., 2000). So, knowing the risk factors of ADR in bulk milk will give information on how to reduce the risk of having ADR in bulk milk, but more research is needed on incentives for farmers to change their habits.

Increased $\mathrm{BAB}$ levels were related to dirty dairy cattle, dirty cubicles for young stock, no free access for cattle to drinking water, a dirty milk pipeline or one that crossed a feed alley, dung place, or cellar, poor management of veterinary drugs and veterinary materials to administer the drugs. Levels of BAB in farm milk originate mainly from grass and corn silage that are fed to cows. The BAB spores accumulate in feces and, via the exterior of the cow's teats contaminated with feces, $\mathrm{BAB}$ is transmitted to milk during milking (Te Giffel et al., 2002). Our results relate to the contamination route of farm milk: if the farm environment was dirty, $\mathrm{BAB}$ levels were increased. However, the most effective way of controlling BAB levels in farm milk is to control the $\mathrm{BAB}$ spore concentration in silage (Vissers et al., 2006, 2007a,b), whereas other hygienic measures such as teat cleaning (Stadhouders and Jorgensen, 1990) are far less effective.

Determination of FPD is used to detect the presence of extraneous water in milk. In the Netherlands there is no incentive to add deliberately water to bulk milk, because farmers are paid for the protein and fat content and not for the total mass of milk. Moreover, farmers pay for the transport of the bulk milk. Therefore, an increased freezing point indicates unintentional addition of water that might be from water that entered the milking lines during milking and cleaning. To reduce the risk of FPD, it is necessary to prevent water entering the milking lines during milking and cleaning. Our results showed that an increased freezing point (or a decreased FPD) is related to many different audit variables, one of which was poor animal well-being management, in which the cubicles were dirty, the housing was in poor condition, and where the feed storage was dirty and wet. None of these variables were an indicator for (unintentional) added water to the bulk milk, but were indicators for the management style of the farmer. Many factors may affect freezing point of milk from individual cows (Sherbon, 1988). High-producing cows might be expected to have higher freezing points than lower producing cows. Diet, as well as how and when the diets are fed relative to collecting the milk sample, may also affect freezing point in individual cows. Little work has been done in recent years to define freezing point on milk from modern high-producing dairy cattle (Sherbon, 1988).

Free fatty acids are products of hydrolysis (lipolysis) of triglycerides, the major lipid components of milk. Lipolysis can be prevented by proper construction and operation of the milking installation (low lying and descending milk lines, no air leaks or entry during pumping). Cows late in lactation or with short milk intervals have elevated levels. Factors that are associated with lipolysis at the farm level are late lactation, poor quality feed, mastitis, agitation, and pumping of raw milk with air incorporation during milking such as excessive air intake at the teat cups (Deeth, 2006). Our results show that higher levels of FFA in bulk milk were associated with a poor management (including maintenance) and the building of the milking parlor or automatic milking 
systems. This is in line with the literature because poor management of the milking equipment may cause agitation of milk and incorporation of air during milking.

Microorganisms can be transmitted to milk via dirt attached to the exterior of the cows' teats. Not much literature exists on factors related to the number of times that this dirt or sediment is found in bulk milk. Vissers et al. (2007c) showed that the amount of dirt transmitted from the exterior to the teats and to the milk varies among farms. They conclude that the role of teat hygiene should not be neglected to reduce the amount of dirt in milk. Our study showed that if the young stock were dirty, drinking management was not adequate and that the number of times that dirt/ sediment is found in farm milk is increased when the veterinary drugs are poorly managed. It may be that young stock hygiene is an indicator of general farm and udder sanitation, although the checklist item "Cattle dirty" and others related to hygiene were not significantly related. No other studies are known that relate to these results.

The estimated associations found in this study did not prove that the observed differences in process control quality (assessed by audits) caused changes in the product control test (farm milk test results). This is because field data cannot be used to distinguish causal from noncausal associations. However, the strength and plausibility of associations are indicators for possible causality. Strength refers to the numerical strength of the correlation, which we showed in the top 15 correlations in Figures 2 to 8 . Plausibility refers to the scientific credibility of a relationship. In this study, the direction of most significant estimates was in line with the common understanding and scientific knowledge about the relationship between checklist items and farm milk test results. However, aberrations were observed. These anomalies may have been occurred because of limited deviant observations from the desired farm situation for some checklist items.

This study is unique because the data set contained extensive information on farm audits (271 checklist items) as well as 7 different laboratory tests of bulk milk samples. Moreover, the 6.5-yr time series comprised 64,373 audit outcomes on 26,953 dairy farms and all conducted laboratory tests of bulk milk samples. Regardless of the richness of the data set, it should be stressed that not all checklist estimates had the same robustness. However, for the majority of checklist elements sufficient variation was present, enabling to estimate significant and robust associations.

Some audit variables were related to all laboratory result variables, whereas some were related to none. Based on the results of this study the audit checklist might be reconsidered and more focused on product quality, which might result in shorter audits and thus more efficient process control. Based on the quantified relations, certification schemes could be improved and made more efficient so that (only) the relevant points are judged. Furthermore, milk quality information could be used as a basis for selecting farms for more or less frequent audits.

\section{CONCLUSIONS}

We conclude that product quality control and process quality control of bulk milk are associated. If dairy farms are assessed negatively on specific audit aspects, bulk milk quality is more likely to be inferior. However, the proportion of the total variance in milk test results explained by audits ranged between 4 and $13 \%$ (depending on the specific bulk milk test), showing that aspects other than audits are associated with test results. Thus, auditing dairy farms provides additional but limited information on the performance of product quality.

\section{ACKNOWLEDGMENTS}

The authors express their gratitude to Sector Boerderijmelk, Qlip NV, Leusden, the Netherlands (Louwrens van Keulen) for funding this study and for providing data, and to Johan Tippe (Qlip NV) for his contribution with respect to interpretation of data, results, and discussion. Furthermore, Hein van Valenberg (product design and quality management group, Wageningen University, Wageningen, the Netherlands) and Toon van Hooijdonk (FrieslandCampina, Amersfoort, the Netherlands) are thanked for reviewing the manuscript.

\section{REFERENCES}

Barbano, D. M., Y. Ma, and M. V. Santos. 2006. Influence of raw milk quality on fluid milk shelf life. J. Dairy Sci. 89(E Suppl.):E15E19.

Barnouin, J., M. Chassagne, S. Bazin, and D. Boichard. 2004. Management practices from questionnaire surveys in herds with very low somatic cell score through a national mastitis program in France. J. Dairy Sci. 87:3989-3999.

Berry, D. P., B. O'Brien, E. J. O'Callaghan, K. O. Sullivan, and W. J. Meaney. 2006. Temporal trends in bulk tank somatic cell count and total bacterial count in Irish dairy herds during the past decade. J. Dairy Sci. 89:4083-4093.

Deeth, H. C. 2006. Lipoprotein lipase and lipolysis in milk. Int. Dairy J. $16: 555-562$.

Elmoslemany, A. M., G. P. Keefe, I. R. Dohoo, and B. M. Jayarao. 2009a. Risk factors for bacteriological quality of bulk tank milk in Prince Edward Island dairy herds. Part 1: Overall risk factors. J. Dairy Sci. 92:2634-2643.

Elmoslemany, A. M., G. P. Keefe, I. R. Dohoo, and B. M. Jayarao. 2009b. Risk factors for bacteriological quality of bulk tank milk in Prince Edward Island dairy herds. Part 2: Bacteria count-specific risk factors. J. Dairy Sci. 92:2644-2652.

Gibbons-Burgener, S. N., J. B. Kaneene, J. W. Lloyd, and R. J. Erskine. 2000. Influence of the milk and dairy beef quality assurance program on dairy farm drug management practices. J. Am. Vet. Med. Assoc. 216:1960-1964. 
Herrick, J. B. 1993. Milk and dairy beef quality assurance program: A food safety issue. J. Am. Vet. Med. Assoc. 203:1389-1399.

ISO. 2004. ISO 21187|IDF 196. Milk-Quantitative determination of bacteriological quality-Guidance for establishing a conversion relationship between routine method results and anchor method results and its verification. International Organisation for Standardisation, Geneva, Switzerland. http://www.iso.org/iso/catalogue_detail.htm?csnumber $=34434$.

ISO. 2006. ISO/TS 26844|IDF/RM 215. Milk and milk products-Determination of antimicrobial residues-Tube diffusion test. International Organisation for Standardisation, Geneva, Switzerland. http://www.iso.org/iso/iso_catalogue/catalogue_tc/catalogue_ detail.htm?csnumber $=43819$.

ISO. 2009. ISO 5764|IDF 108. Milk - Determination of freezing pointThermistor cryoscope method (Reference method). International Organisation for Standardisation, Geneva, Switzerland. http:// www.iso.org/iso/iso_catalogue/catalogue_tc/catalogue_detail. htm? csnumber $=43986$.

Meuwissen, M. P. M., A. G. J. Velthuis, H. Hogeveen, and R. B. M. Huirne. 2003. Traceability and certification in meat supply chains. J. Agribus. 21:167-181.

Nightingale, C., K. Dhuyvetter, R. Mitchell, and Y. Schukken. 2008. Influence of variable milk quality premiums on observed milk quality. J. Dairy Sci. 91:1236-1244.

Nouws, J., H. Van Egmond, I. Smulders, G. Loeffen, J. Schouten, and H. A. Stegeman. 1999. Microbiological assay system for assessment of raw milk exceeding EU maximum residue levels. Int. Dairy J. 9:85-90.

Pantoja, J. C. F., D. J. Reinemann, and P. L. Ruegg. 2009. Associations among milk quality indicators in raw bulk milk. J. Dairy Sci. 92:4978-4987.

Schukken, Y. H., K. E. Leslie, A. J. Weersink, and S. W. Martin. 1992. Ontario bulk milk somatic cell count reduction program. 1. Impact on somatic cell counts and milk quality. J. Dairy Sci. 75:3352-3358.

Sherbon, J. W. 1988. Physical properties of milk. Pages 409-460 in Fundamentals of Dairy Chemistry. Vol. 3. I. Wong and P. Noble, ed. Aspen Publishers, New York, NY.

Sischo, W. M., N. E. Kiernan, C. M. Burns, and L. I. Byler. 1997. Implementing a quality assurance program using a risk assessment tool on dairy operations. J. Dairy Sci. 80:777-787.
Stadhouders, J., and K. Jorgensen. 1990. Prevention of the contamination of raw milk by a hygienic milk production. Bull. Int. Dairy Fed. 251:32-36.

Te Giffel, M. C., A. Wagendorp, A. Herrewegh, and F. Driehuis. 2002. Bacterial spores in silage and raw milk. Antonie van Leeuwenhoek 81:625-630.

Valeeva, N. I., T. J. G. M. Lam, and H. Hogeveen. 2007. Motivation of dairy farmers to improve mastitis management. J. Dairy Sci. 90:4466-4477.

van Schaik, G., M. Lotem, and Y. H. Schukken. 2002. Trends in somatic cell counts, bacterial counts, and antibiotic residue violations in New York State During 1999-2000. J. Dairy Sci. 85:782-789.

Veerkamp, R. F., A. W. Stott, W. G. Hill, and S. Brotherstone. 1998. The economic value of somatic cell count payment schemes for UK dairy cattle breeding programmes. Anim. Sci. 66:293-298.

Velthuis, A. G. J., M. Meuwissen, and R. B. M. Huirne. 2009. Distribution of direct recall costs along the milk chain. Agribusiness 25:466-479.

Velthuis, A. G. J., M. W. Reij, K. Baritakis, M. Dang, and C. P. A. van Wagenberg. 2010. Recall costs balanced against spoilage control in Dutch custard. J. Dairy Sci. 93:2779-2791.

Vissers, M. M. M., F. Driehuis, M. C. Te Giffel, P. De Jong, and J. M. G. Lankveld. 2006. Improving farm management by modeling the contamination of farm tank milk with butyric acid bacteria. J. Dairy Sci. 89:850-858.

Vissers, M. M. M., F. Driehuis, M. C. Te Giffel, P. De Jong, and J. M. G. Lankveld. 2007a. Concentrations of butyric acid bacteria spores in silage and relationships with aerobic deterioration. J. Dairy Sci. 90:928-936.

Vissers, M. M. M., F. Driehuis, M. C. Te Giffel, P. De Jong, and J. M. G. Lankveld. 2007b. Minimizing the level of butyric acid bacteria spores in farm tank milk. J. Dairy Sci. 90:3278-3285.

Vissers, M. M. M., F. Driehuis, M. C. Te Giffel, P. De Jong, and J. M. G. Lankveld. 2007c. Short Communication: Quantification of the transmission of microorganisms to milk via dirt attached to the exterior of teats. J. Dairy Sci. 90:3579-3582. 